\title{
Cross-cultural adaptation of the Posttraumatic Stress Disorder Checklist 5 (PCL-5) and Life Events Checklist 5 (LEC-5) for the Brazilian context
}

\author{
Adaptação transcultural da Posttraumatic Stress Disorder Checklist 5 (PCL-5) e \\ da Life Events Checklist 5 (LEC-5) para o contexto brasileiro
}

Eduardo de Paula Lima, ${ }^{1}$ Alina Gomide Vasconcelos, ${ }^{1}$ William Berger, ${ }^{2}$ Christian Haag Kristensen, ${ }^{3}$ Elizabeth do Nascimento, ${ }^{1}$ Ivan Figueira, ${ }^{2}$ Mauro Vitor Mendlowicz ${ }^{4}$

\begin{abstract}
Objective: To describe the process of cross-cultural adaptation of the Posttraumatic Stress Disorder Checklist 5 (PCL-5) and the Life Events Checklist 5 (LEC-5) for the Brazilian sociolinguistic context. Method: The adaptation process sought to establish conceptual, semantic, and operational equivalence between the original items of the questionnaire and their translated versions, following standardized protocols. Initially, two researchers translated the original version of the scale into Brazilian Portuguese. Next, a native English speaker performed the back-translation. Quantitative and qualitative criteria were used to evaluate the intelligibility of items. Five specialists compared the original and translated versions and assessed the degree of equivalence between them in terms of semantic, idiomatic, cultural and conceptual aspects. The degree of agreement between the specialists was measured using the content validity coefficient (CVC). Finally, 28 volunteers from the target population were interviewed in order to assess their level of comprehension of the items. Results: CVCs for items from both scales were satisfactory for all criteria. The mean comprehension scores were above the cutoff point established. Overall, the results showed that the adapted versions' items had adequate rates of equivalence in terms of concepts and semantics.

Conclusions: The translation and adaptation processes were successful for both scales, resulting in versions that are not only equivalent to the originals, but are also intelligible for the population at large.

Keywords: Posttraumatic stress disorder, life-changing events, scales, Posttraumatic Stress Disorder Checklist 5, Life Events Checklist 5.
\end{abstract}

\section{Resumo}

Objetivo: Descrever o processo de adaptação transcultural das escalas Posttraumatic Stress Disorder Checklist 5 (PCL-5) e Life Events Checklist 5 (LEC-5) para o contexto sociolinguístico brasileiro.

Método: A adaptação das escalas buscou estabelecer a equivalência conceitual, semântica e operacional entre os itens originais das escalas e suas versões traduzidas, por meio de um protocolo padronizado. Inicialmente, dois pesquisadores traduziram as versões originais para o português. Na sequência, um falante nativo de língua inglesa realizou a tradução reversa. A inteligibilidade dos itens foi analisada por meio de critérios quantitativos e qualitativos. Cinco especialistas compararam as versões originais e traduzidas e avaliaram o grau de equivalência entre elas nos quesitos semântico, idiomático, cultural e conceitual. $\mathrm{O}$ grau de concordância entre os especialistas foi medido pelo coeficiente de validade de conteúdo (CVC). Por fim, 28 voluntários da população-alvo foram entrevistados para verificar o nível de compreensão dos itens.

Resultados: Os itens das duas escalas apresentaram CVCs satisfatórios em todos os quesitos. Os escores médios referentes ao grau de compreensão dos itens foram acima do ponto de corte estabelecido. No conjunto, os resultados indicaram índices adequados de equivalência conceitual e semântica para os itens das versões adaptadas. Conclusão: $O$ processo de tradução e adaptação foi bem-sucedido para as duas escalas, resultando em versões não apenas equivalentes às originais, mas também compreensíveis para a população-alvo em geral.

Descritores: Transtorno de estresse pós-traumático; acontecimentos que mudam a vida; escalas; Posttraumatic Stress Disorder Checklist 5, Life Events Checklist 5.

\footnotetext{
${ }^{1}$ Universidade Federal de Minas Gerais (UFMG), Belo Horizonte, MG, Brazil. . Universidade Federal do Rio de Janeiro (UFRJ), Rio de Janeiro, RJ, Brazil. ${ }^{3}$ Pontifícia Universidade Católica do Rio Grande do Sul (PUCRS), Porto Alegre, RS, Brazil. ${ }^{4}$ Universidade Federal Fluminense (UFF), Niterói, RJ, Brazil. Financial support: Conselho Nacional de Desenvolvimento Científico e Tecnológico (CNPq; grant no. 447091/2014-0).

Submitted Oct 29 2015, accepted for publication Mar 09 2016. No conflicts of interest declared concerning the publication of this article.

Suggested citation: Lima EP, Vasconcelos AG, Berger W, Kristensen CH, Nascimento E, Figueira I, Mendlowicz MV. Cross-cultural adaptation of the Posttraumatic Stress Disorder Checklist 5 (PCL-5) and Life Events Checklist 5 (LEC-5) for the Brazilian context. Trends Psychiatry Psychother. 2016;38(4):207-215. http:// dx.doi.org/10.1590/2237-6089-2015-0074
} 


\section{Introduction}

Posttraumatic stress disorder (PTSD) is a mental disorder resulting from the exposure of a person to death or threatened death and actual or threatened serious injury, or sexual violence. ${ }^{1}$ Posttraumatic stress disorder was formally recognized in the DSM-III (1980), but its diagnostic criteria have been repeatedly revised in the subsequent editions of the Diagnostic and Statistical Manual of Mental Disorders (DSM). ${ }^{1-5}$

The main changes to the diagnostic criteria for PTSD in the fifth edition of the $\mathrm{DSM}^{1}$ were as follows: 1) PTSD was moved into a new nosological category, labeled "trauma and stressor-related disorders"; 2) PTSD criterion A became more explicit and restrictive with regard to what constitutes a traumatic event; 3 ) the need to evaluate the individual's subjective reaction (i.e., intense fear, helplessness, or horror) to characterize the traumatic event was removed from the criteria (previously criterion A2 in the DSMIV); 4) the number and type of typical symptoms of PTSD were altered; 5) the three original clusters were divided into four in the DSM-5; 6) cognitive, affective and physiological factors that may make the individual more vulnerable to developing PTSD were acknowledged in reference to symptoms that began, or worsened after the traumatic event; 7) more attention was paid to the disorder's developmental aspects regarding specifications of the symptoms in children, including a distinct set of diagnostic criteria for children younger than 7 years old; and 8) a new dissociative subtype of PTSD was created.

The recent changes in the definition and diagnostic criteria of PTSD created an urgent need to revise the instruments available to measure the construct. Structured instruments for assessing symptoms and morbidity rely either on interviews or self-report scales, with the latter being used more often due to their practicality and low cost. ${ }^{6}$ In 2013, Weathers et al. revised two self-report scales that have been widely used in clinical and research settings, namely the Posttraumatic Stress Disorder Checklist (PLC) 7 and the Life Events Checklist (LEC). ${ }^{8}$ These revisions resulted in two new instruments, the Posttraumatic Stress Disorder Checklist 5 (PCL-5), ${ }^{9}$ for evaluation of the presence and intensity of typical PTSD symptoms, and the Life Events Checklist 5 (LEC-5), ${ }^{10}$ focused on measuring exposure to traumatic events.

The PCL-5 was developed to assess PTSD symptoms according to criteria $B, C, D$, and $E$ of the DSM-5. ${ }^{1}$ It comprises 20 items, the responses to which are given along a 5-point Likert-type intensity scale, ranging from zero (not at all) to four (extremely). The respondent is asked to indicate how much he/she has been disturbed by PTSD symptoms during the previous month. The PCL-5 can be applied in three ways: 1 ) without considering criterion $A$; 2 ) preceded by a brief evaluation of criterion $A$; or 3 ) preceded by a detailed assessment of criterion A (carried out using the LEC5). There are two possibilities for identification of probable cases of PTSD. The first is based on the DSM5 diagnostic criteria for PTSD: at least one criterion B symptom (items 1 to 5 ), one criterion $C$ symptom (items 6 and 7), two criterion D symptoms (items 8 to 14 ), and two criterion E symptoms (items 15 to 20). Symptoms are only considered present for items with a moderate to high intensity score $(\geq 2)$. The second possibility for identification of probable cases is based on the total score of the scale. For example, a study

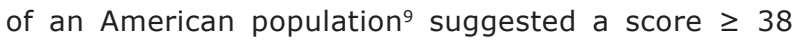
indicates PTSD probable cases.

The LEC-5 comprises 17 items and is designed to investigate exposure to potentially traumatic events meeting diagnostic criterion A for PTSD according to the DSM-5. ${ }^{1}$ These items include life events such as natural disasters, physical or sexual aggression, severe injuries, violent death (homicide or suicide), and others. For each situation, the respondent is asked to indicate the type of exposure (i.e., whether he/she experienced the event directly or witnessed an event or situation involving a close relative or friend and if it was related to occupational activities). The LEC-5 also identifies the most traumatic event ever experienced by the respondent, when this event occurred, and how many times similar events have occurred during the respondent's lifetime. ${ }^{10}$

Although the PCL- 5 and LEC-5 are already available in English, there aren't any DSM-5 criteria-based selfreport instruments for PTSD in the Brazilian Portuguese language. The objective of this study was therefore to perform a cross-cultural adaptation of the PCL-5 and the LEC-5 for the Brazilian context by assessing the items' conceptual, semantic and operational equivalence. In order to ensure that the Brazilian Portuguese version is aligned with the original one, the present study recruited and assessed a population sample that was heterogeneous in terms of age, educational level, and occupation, and was made up of people living in three of the most important Brazilian state capitals (Belo Horizonte, Rio de Janeiro and Porto Alegre).

\section{Methods}

The cross-cultural adaptations of both scales were based on a model proposed by Reichenheim \& Moraes, ${ }^{11}$ 
consisting of three sequential steps: 1 ) selection of the scales; 2) conceptual and semantic equivalence; and 3) operational equivalence.

\section{Translation and adaptation procedures}

\section{Step 1: Selection of the scales}

The PCL-5 and LEC-5 were selected for adaptation on the basis of a review of the literature. This step consisted of seeking instruments for assessment of PTSD and analyzing the correspondence between the DSM-5 diagnostic criteria and the scales' instructions and items. The following descriptors (Mesh/DeCS) were used in the search for references: PTSD, scales, psychological tests, and psychological test validity.

\section{Step 2: Conceptual and semantic equivalence}

This step was performed in four phases, namely: 1) translation from English into Portuguese; 2) backtranslation from Portuguese into English; 3) analysis of the cross-linguistic equivalence by an expert panel; and 4) discussions with people who are representative of the target population.

In phase 1 (translation), the original scales were translated into Portuguese by two Brazilian psychologists, both fluent in English. The translations were performed independently, resulting in two preliminary Brazilian Portuguese versions of the PCL- 5 and the LEC-5 (T1 and T2). Next, the T1 and T2 versions were evaluated and compared by two of the authors of the present study (EPL and AGV). Whenever necessary, $\mathrm{T} 1$ and $\mathrm{T} 2$ items were changed or refined, and the two versions were then merged to create a single properlytranslated version for each of the instruments (SV). The final analysis of items was performed based on criteria proposed by Pasquali, ${ }^{12}$ which emphasizes the need for simplicity, clarity, relevance and credibility of self-report questionnaire items.

In phase 2 (back-translation), the PCL-5 and LEC$5 \mathrm{SVs}$ were translated back into English by a native English speaker who is fluent in Portuguese and neither participated in phase 1 nor had any prior knowledge about the instruments. The person who performed the back-translation (BT) is a U.S. citizen who has been living in Brazil for 14 years and holds a doctoral degree in the area of healthcare. Finally, the BT versions of PCL-5 and LEC-5 were evaluated for semantic and conceptual equivalence by one of the authors of the original scales (Frank W. Weathers FWW).

Phase 3 (formal analysis of the equivalence) was conducted by an expert panel consisting of five psychiatrists and one psychologist, all of whom had extensive experience in cross-validation of psychometric instruments and in assessing and treating PTSD patients. They were instructed to compare the translated versions of the scales (SV) to the original versions in English. For this task, they received a standardized questionnaire specifically created for the present study, entitled Questionnaire for the Expert Panel (for further details, see the Instruments subsection below).

In the fourth phase (discussions with the target population), brief interviews were conducted to assess general understanding of items on the questionnaires. The sample consisted of individuals from three Brazilian state capitals (Belo Horizonte, MG; Rio de Janeiro, $\mathrm{RJ}$; and Porto Alegre, RS) and was heterogeneous from a socio-demographic standpoint. Subjects with low levels of educational attainment (elementary school only) were included in the assessment to probe their comprehension of the instructions and of the items. Additionally, individuals who had at least graduated from high school were evaluated to ensure that the scales were also considered suitable for individuals with higher educational levels. This strategy was intended to increase the face validity of the instruments. ${ }^{12}$ A standardized questionnaire, entitled Questionnaire for Discussion with the Target Population (see the Instruments subsection below) was developed specifically for this task. Volunteers were asked about the ease of comprehension and relevance of the items and comments and suggestions were encouraged and recorded.

\section{Step 3: Operational equivalence}

Operational equivalence was confirmed during meetings held by the authors of the present study. After discussions with representatives of the target population, their suggestions and remarks were analyzed. Issues such as the format of the scales, context (clinical vs. non-clinical) and form of application (individual or collective; self-report or interview) were taken into account. After modifications and refinements, the final versions of PCL- 5 and LEC5 adapted for the Brazilian context were approved (Appendix 1, available online only). The three steps described above are illustrated schematically in Figure 1.

\section{Subjects}

We used a convenience sample stratified by city and educational level. Volunteers were recruited from educational institutions (elementary, middle and high school) and from service provider companies. 


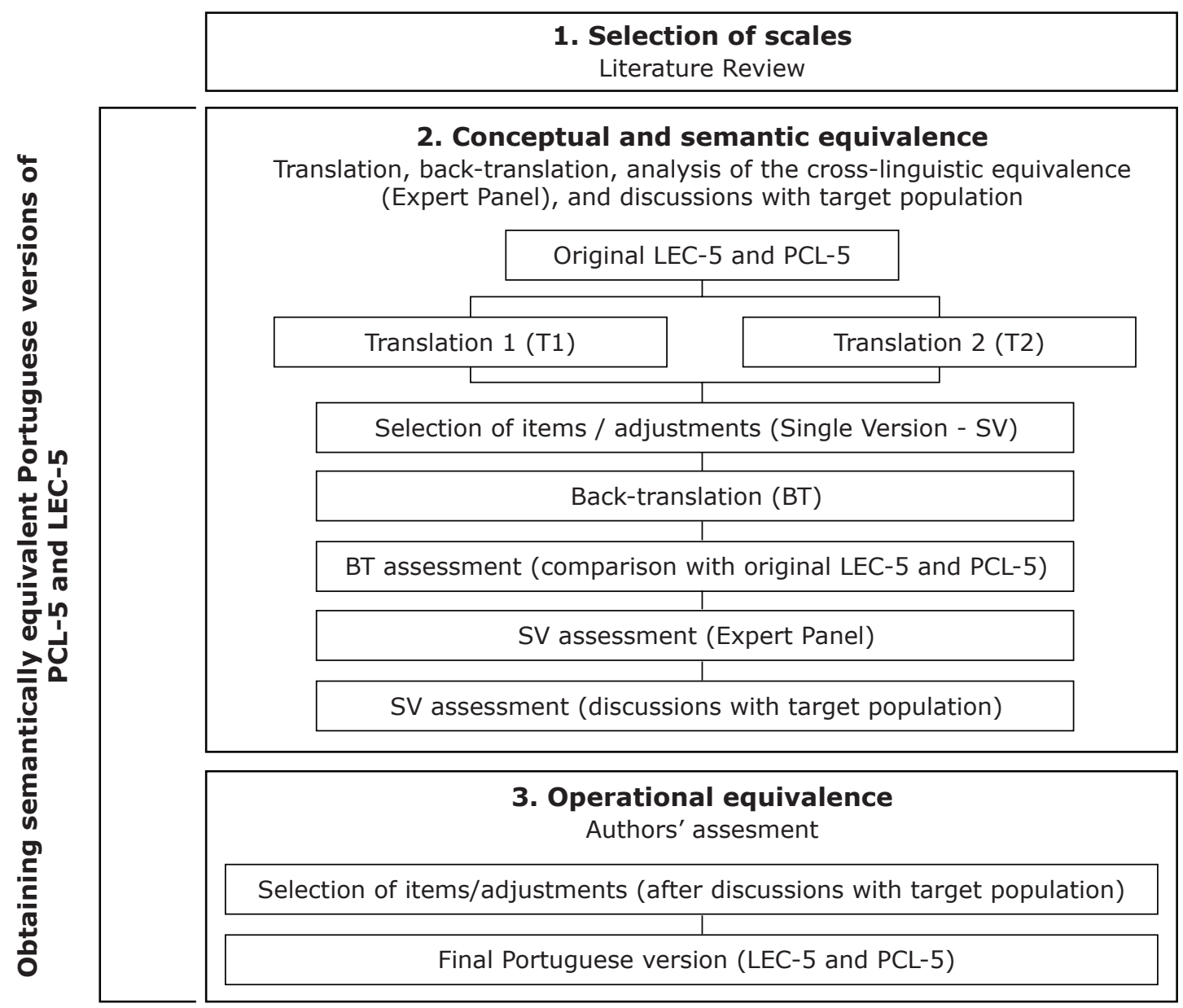

Figure 1 - Translation and cross-cultural adaptation of the LEC- 5 and the PCL- 5 for the Brazilian context. LEC-5 = Life Events Checklist 5; PCL-5 = Posttraumatic Stress Disorder Checklist 5.

The sample consisted of 28 adult individuals (over the age of 18), all born in Brazil. The sample was heterogeneous in terms of sex distribution (18 women and 10 men), educational attainment (two volunteers with primary education level; 13 with secondary education level; and 13 with higher education level) and city of residence (11 subjects living in Belo Horizonte, MG; 8 in Rio de Janeiro, RJ; and 9 in Porto Alegre, RS). With regard to occupation, it should be noted that five subjects were selected because they worked for emergency services (fire or police department). This criterion was adopted to help evaluate the following issues: 1) comprehension of the items by individuals who are often exposed to traumatic events; and 2) possible biases in the understanding of certain items, particularly those concerning the phenomenon of hypervigilance (e.g., alterations in arousal and reactivity), as recommended elsewhere. ${ }^{13,14}$

\section{Instruments}

In addition to the English versions of the PCL-5 and the LEC-5, two additional questionnaires were developed for use in the present study and employed to investigate the equivalence and comprehension of the scale items.

\section{Questionnaire for the Expert Panel}

This questionnaire consists of a set of items from the original and from the translated versions of each scale. After each item from the PCL-5 and the LEC-5, questions were posed on their semantic (meaning of the words, vocabulary and grammar), cultural (terms used and events experienced by the population), idiomatic (use of idiomatic and colloquial expressions) and conceptual (construct proposed in the original instrument) equivalence. For this evaluation, the 
specialists compared the items from both versions and rated them according to a 3-point Likert scale, namely: $0=$ there is no equivalence between the versions; 1 = indecision; and 2 = there is equivalence between the versions. In cases of lack of equivalence between the versions, the specialists were asked to make suggestions to improve it.

\section{Questionnaire for discussion with the Target Population}

This is an instrument consisting of items from the single translated version (SV) of the PCL-5 and LEC5 , after suggestions made by the expert panel. The respondents were instructed as follows:

Please, read the sentences and indicate how well you understand each one by scoring them from 1 ("I did not understand anything") to 5 ("I understood everything"). For example, if, after reading the sentence "Somebody was severely injured or killed in the accident" you think that you fully understood the content, you should mark choice 5 ("I understood everything"). However, if you read the sentence and did not understand what was written, you should mark option 1 ("I did not understand anything").

For those items on which the specialists had not reached a consensus in the earlier phase, the subjects were instructed to indicate the best choice of translation from those shown. Comments and suggestions were requested for improving any potentially problematic items.

\section{Procedures for data analysis}

The analyses of the translation (EPL, AGV) and of the back-translation (FWW), and the final adjustments of the scales (carried out by all authors) were qualitative and aimed at ensuring equivalence to the diagnostic criteria established by the DSM- $5,{ }^{1}$ while respecting the standard recommendations for translation and item construction. ${ }^{11,12,15}$ Nevertheless, quantitative criteria were used to analyze the questionnaires filled out by the expert panel. The specialists' answers were analyzed by calculating the rate of agreement between experts using the content validity coefficient (CVC). ${ }^{16}$ The results were transformed into scores according to the following criteria: score 3 (item is equivalent); score 2 (item caused indecision); and score 1 (item is not equivalent). The acceptable cutoff point for CVC was set at $0.80 . .^{16}$

Data obtained from the target population on the intelligibility of the items were quantitatively analyzed by calculating scores for central tendency (mean) and dispersion (standard deviation) for each item. A mean score $\geq 3$ was established as the criterion for satisfactory comprehension. ${ }^{16}$ Remarks and suggestions made by the subjects were recorded and then discussed by the authors during preparation of the final version of the two scales.

\section{Ethical aspects}

The invitation to participate in the study included information on the objectives as well as on the voluntary and confidential nature of the research. All the participants signed a free and informed consent form before filling out the scales. The study was approved by the Research Ethics Committee at the Universidade Federal de Minas Gerais (certificate number: 15169813.1.0000.5149).

\section{Results}

Assessment of the original versions of the LEC5 and the PCL-5 (step 1) showed that the scales are coherent with the diagnostic criteria for traumatic events and symptoms of PTSD proposed by the DSM5 , respectively. ${ }^{1}$

With regard to the equivalence of concepts, items and semantics (step 2), the assessment of the initial translations of each scale ( $\mathrm{T} 1$ and $\mathrm{T} 2$ ) resulted in satisfactory SVs for both scales. The back-translated (BT) versions of the PCL-5 and the LEC-5 were fully approved by the first author of the original scales (FWW). This result supported the initial evidence for the equivalence between the original versions, SV and BT.

Formal assessment of equivalence by experts indicated a satisfactory degree of concordance on translated items, as measured by CVC scores. In fact, all items had CVC scores equal to or greater than 0.80 for semantic, cultural and conceptual criteria, including the final CVC. Even so, changes were made to some items and instructions in response to the experts' comments and suggestions. ${ }^{16}$ For instance:

1) The word "stressful," which had been translated as "estressante," was changed to "traumatizante" because the latter was considered more appropriate for the context.

2) The verb "to experience," employed in the instructions and in several items of the scales, was initially translated as "experienciar." However, the specialists suggested using the verb "vivenciar" because it was considered more easily intelligible for the general population ("How did you experience the event?"/"Como você vivenciou o evento?"). 
3) The expression "first responder," which had originally been translated as "profissionais de emergência," was replaced with "socorristas." This change was justified because a wide spectrum of first aid workers are usually involved in major impact events (expression used in the instructions within the PCL-5 and LEC-5).

4) The expression "taking too many risks" (item 17 from the PCL-5), initially translated as "assumir muitos riscos" was replaced with "arriscar-se muito." This change was intended to emphasize a sense of recklessness consistent with the clinical depiction of PTSD in the DSM- 5 .

5) The expression "severe human suffering" (item 13 from the LEC-5), initially translated as "sofrimento humano grave," was changed to "experiência de sofrimento físico grave ou intenso." This change was justified on the basis that it was more coherent with the concept of traumatic event.

6) The instruction "check all options that apply," initially translated as "verifique todas as opções que se aplicam," was changed to "marque todas as opções que se aplicam."

7) The item "Being superalert or watchful or on guard?," initially translated as "Estar superalerta, vigilante ou em guarda?," was changed to "Estar superalerta ou hipervigilante?". This change was the result of the discussions with firefighters and policemen. These interviewees were unanimous on the use of the term "on guard." For them, the term has a positive connotation that reflects an attitude that is expected from these workers. This attitude is pervaded by institutional values (fire brigade and police departments) that are learned in their training courses and reinforced by their daily interactions with superiors, peers and subordinates.

The experts also suggested changes to some items depicting the most common types of catastrophe in Brazil. For instance, the natural disasters listed in the first item of the PCL-5 (hurricane, tornado, earthquake) were replaced for "deslizamento de terra, desabamento," (landslide and buildings collapsing, respectively) which are situations closer to the traumatic events most often experienced by the Brazilian population. Item 10 of the LEC- 5 refers to exposure to war events, but the experts proposed changing it to "Combate ou exposição a uma área de guerra ou de conflitos urbanos violentos (ex: militar ou civil)."

In the discussions with the target population, all mean scores for the level of comprehension of the items were above the cutoff point $(>3)$. These results suggest that the items and instructions were satisfactorily understood, regardless of the educational level of the respondents. In items with two or more options (where alternatives had been suggested by the expert panel), subjects were instructed to select the one most likely to be understood. In these cases, the alternative with the highest response rate was adopted. The results are listed in Table 1.

Table 1 - Items selected for detailed evaluation during the phase of discussions with the target population, their respective suggested alternatives and the final versions chosen

\begin{tabular}{ll}
\hline Item 9 (LEC-5) & Translated version: Outras experiências sexuais indesejadas ou desconfortáveis \\
Other unwanted or uncomfortable sexual & Suggestions: Outras experiências sexuais indesejadas ou desconfortáveis/não consentidas. \\
experience & Final version: Outras experiências sexuais indesejadas ou não consentidas. \\
Item 15 (LEC-5) & Translated version: Morte acidental repentina. \\
Sudden accidental death & Suggestions: Morte acidental repentina/inesperada/súbita. \\
& Final version: Morte acidental inesperada. \\
Item 14 (PCL-5) & Translated version: Dificuldades para experimentar sentimentos positivos (por exemplo, \\
Trouble experiencing positive feelings (for & ser incapaz de sentir felicidade ou ter sentimentos amorosos pelas pessoas próximas a \\
example, being unable to feel happiness or have & você)? \\
loving feelings for people close to you)? & Suggestions: (...) ter sentimentos amorosos/afetuosos/amigáveis/positivos (...) \\
& $\begin{array}{l}\text { Final version: Dificuldades para experimentar sentimentos positivos (por exemplo, ser } \\
\text { incapaz de sentir felicidade ou de ter sentimentos afetuosos pelas pessoas próximas a }\end{array}$ \\
& você). \\
Item 17 (PCL-5) & Translated version: Estar "superalerta," vigilante ou "em guarda"? \\
Being "superalert" or watchful or on guard? & Suggestions: No suggestions. \\
& Final version: Estar "superalerta" ou hipervigilante.
\end{tabular}

LEC-5 = Life Events Checklist 5; PCL-5 = Posttraumatic Stress Disorder Checklist 5.

The assessment of operational equivalence considered the format of the scale (i.e., the presentation of instructions, items, and response scales) and its applicability to clinical and research contexts. The final formats of the PCL-5 and the LEC- 5 were deemed compatible with the original scales. 


\section{Discussion}

The present study is a pioneer in having conducted cross-cultural adaptation of the PCL- 5 and the LEC- 5 for the Brazilian sociolinguistic context. As part of the adaptation, conceptual, item, semantic and operational equivalence between the original and adapted versions of the instruments were assessed. The intelligibility of the translated versions was analyzed using quantitative (CVC calculation) and qualitative (suggestions by experts and individuals from the target population) criteria. Additionally, one of the authors of the original instruments (FWW) supervised the undertaking. Several Brazilian specialists in trauma and PTSD from three different state capitals also participated in this effort, some of whom were responsible for semantic adaptation to the Brazilian context of an earlier version of the PCL-C, ${ }^{17}$ based on the DSM-IV.

We chose the PCL-5 and the LEC-5 for crosscultural adaptation, rather than other instruments with similar purposes, since they are relatively brief scales (consisting of 17 and 20 items respectively), are easy to administrate and were created for use in the general population by the U.S. Department of Veterans Affairs' National Center for PTSD.9,10 The previous versions (PCL and LEC), based on DSM-IV criteria, had adequate psychometric properties. ${ }^{7,17,18}$ Additionally, the LEC is the most widely-used self-report instrument for assessment of potentially traumatic events in adults. ${ }^{19,20}$ It is also one of the few scales of its type whose psychometric properties have already been critically evaluated. ${ }^{17,19}$ The original PCL-C was cross-translated and validated in several languages, ${ }^{21}$ including Brazilian Portuguese. $6,13,14$

Investigations have demonstrated that the original PCL-5 is psychometrically sound. The scale was administered to samples of trauma-exposed college students ${ }^{22}$ and US veterans. ${ }^{23}$ The results indicated good internal consistency, satisfactory temporal reliability, and significant correlations with measures of other constructs (convergent and discriminant validity). Nevertheless, there were a few controversies with relation to its factor structure. The DSM-5 model had an adequate fit in both studies. However, Bovin et al. ${ }^{23}$ highlighted that data were best explained by a 6-factor anhedonia model and a 7-factor hybrid model. Finally, compared to a structured psychiatric interview (Clinician-Administered PTSD Scale for DSM-5, CAPS5), PCL-5 scores of 31 to 33 were considered a good cutoff point for detecting probable cases of PTSD according to current DSM criteria. ${ }^{23}$

The cross-cultural adaptation of any psychometric instrument is a complex process because it encompasses a survey of equivalence, evidence of content, format, and comprehension of the translated items as well as psychometric evidence of scores, especially with regard to construct validity. ${ }^{15,24,25}$ It is important to emphasize that this process should be understood as going beyond the mere literal translation of the items, since there is no guarantee that a translated version will be equivalent to the original in terms of content, level of difficulty, or intelligibility. ${ }^{15}$ Consequently, in the present study several methodological procedures were used to obtain evidence of the content validity of the Portuguese versions of the PCL- 5 and LEC- 5 after adaptation to the Brazilian socio-linguistic context.

Firstly, we can conclude that the original construct, as presented in the original versions of the two instruments, was preserved according to the qualitative evaluation of the back-translation performed by one of their original authors (FWW), who endorsed the final product at this stage. However, although many studies only use back-translation, this procedure is not enough to guarantee equivalence between original and adapted versions. ${ }^{26}$ Supplementary procedures were therefore needed. A literal translation of the items can contribute to the adequacy of the back-translation, but it does not ensure that cultural differences in values and meanings have been adequately considered. ${ }^{26}$ Therefore, other strategies are recommended to clarify whether there are distortions in comprehension of the content of items in the language into which they have been translated. ${ }^{16,26}$

For the second step of the present study (conceptual and semantic equivalence), care was taken to recruit researchers from different Brazilian cities who have extensive clinical experience with PTSD patients. The goal was to develop Brazilian Portuguese versions of instruments that investigate the same concepts as the original versions, while considering comprehension of the items, use of colloquial expressions, and use of common terms, and culture-specific life experiences in the Brazilian setting. ${ }^{15}$ A consensus was reached among this group of experts, who had been recruited from different parts of Brazil in order to minimize regional biases in the linguistic expressions used in the scales.

The expert panel used a quantitative measurement (CVC calculation) of validity, arriving at a satisfactory degree of agreement in assessment of the equivalence of the adapted versions in terms of several criteria (i.e., semantic, idiomatic, cultural and conceptual). Nevertheless, some adjustments were made during the qualitative analysis. The translation of item 17 (symptoms of hypervigilance) from PCL-5 is a very illustrative example of the benefits of these comments and suggestions to the process of refinement of the final Brazilian Portuguese versions. One of the experts called attention to a possible interpretation bias among 
policemen and firemen of the expression "em guarda," including in terms of psychometric problems with an earlier Brazilian Portuguese version of the PCL tested with a sample of rescuers. ${ }^{13}$ These considerations, in combination with the observations made by Castro \& Adler ${ }^{27}$ regarding the difficulties of comparing emergency professionals to the general population, justify the inclusion of policemen and firefighters in the sample. The point raised by the experts was corroborated in the discussion process and so the final Brazilian Portuguese version of the item was modified, as described in the Results section of this paper.

Finally, discussions with the target population showed that a heterogeneous sample of Brazilian individuals was able to not only understand the scale items, but also to help the research team to choose the best options among those proposed by the specialists for adaptation of the items. ${ }^{15}$ At the end of this process, Brazilian Portuguese versions of PCL-5 and LEC- 5 had been developed and adapted to the general Brazilian population.

Despite the methodological rigor employed in the present study, some limitations remain. The intelligibility of the scales was tested with a small heterogeneous sample comprising people from the cities of Belo Horizonte, Rio de Janeiro and Porto Alegre, which was not representative of the entire Brazilian population. On the one hand, considering the simplicity of the vocabulary used in the scales, it is unlikely that samples of the Brazilian population (whose mother tongue is Portuguese) would not correctly understand the meaning of the items chosen. On the other hand, this assumption can only be confirmed by studies with different Brazilian populations. ${ }^{15}$ Finally, future studies will be needed to assess the psychometric properties of both scales, such as evidence of criterion and convergent validity, test-retest reliability, and factorial structure of the PCL-5, in order to evaluate whether their items replicate the symptom clusters model proposed by the DSM-5. Psychometric studies are underway to achieve these aims.

As a result, it can be concluded that these versions of the PCL-5 and the LEC-5 have been appropriately translated and exhibit satisfactory content validity for use in Brazil. The cross-cultural adaptation of these scales will enable Brazilian researchers to investigate the presence of trauma and PTSD symptoms by using equivalent measurements (with respect to the original English language versions) based on the more up-todate diagnostic criteria (DSM-5). The efforts made in the present study were necessary to enable comparison of results of the PCL- 5 and LEC- 5 from different populations and for cross-national comparisons. ${ }^{15,24}$

\section{Acknowledgements}

This research was partially supported by Conselho Nacional de Desenvolvimento Científico e Tecnológico (CNPq; grant no. 447091/2014-0). Christian Haag Kristensen, Elizabeth do Nascimento, Ivan Figueira, and Mauro Vitor Mendlowicz are partially supported by grants from CNPq.

The authors would like to thank Frank W. Weathers for evaluating the back-translation of the LEC- 5 and PCL-5 for this study. We would like to thank Julia Luiza Schäfer for the English revision of the final version.

\section{References}

1. American Psychiatric Association. Diagnostic and Statistical Manual of Mental Disorders, Fifth Edition (DSM-5). Arlington: American Psychiatric Publishing; 2013.

2. American Psychiatric Association. Diagnostic and Statistical Manual of Mental Disorders, Fourth Edition, Text Revision (DSMIV-TR). Arlington: American Psychiatric Publishing; 2000.

3. American Psychiatric Association. Diagnostic and Statistica Manual of Mental Disorders, Fourth Edition (DSM-IV). Arlington: American Psychiatric Publishing; 1994.

4. American Psychiatric Association. Diagnostic and Statistica Manual of Mental Disorders, Third Revised Edition (DSM-III-R). Washington: American Psychiatric Association; 1987.

5. American Psychiatric Association. Diagnostic and Statistical Manual of Mental Disorders, Third Edition (DSM-III). Washington: American Psychiatric Publishing; 1980.

6. Lima Ede P, Barreto SM, Assunção AA. Factor structure, internal consistency and reliability of the Posttraumatic Stress Disorder Checklist (PCL): an exploratory study. Trends Psychiatry Psychother. 2012;34:215-22.

7. Weathers FW, Litz BT, Herman D, Huska JA Keane TM. The PTSD Checklist (PCL): reliability, validity, and diagnostic utility. In: Annual Meeting of International Society for Traumatic Stress Studies; 1993; San Antonio: Texas.

8. Blake DD, Weathers FW, Nagy LM, Kaloupek DG, Gusman FD, Charney DS, et al. The development of a Clinician-Administered PTSD Scale. J Trauma Stress. 1995;8:75-90.

9. Weathers FW, Litz BT, Keane TM, Palmieri PA, Marx BP, Schnurr PP. The PTSD Checklist for DSM-5 (PCL-5) [Internet]. 2013 [cited $2016 \mathrm{Apr}$ 25]. http://www.ptsd.va.gov/professional/ assessment/adult-sr/ptsd-checklist.asp

10. Weathers FW, Blake DD, Schnurr PP, Kaloupek DG, Marx BP Keane TM. Life Events Checklist for DSM-5 (LEC-5) [Internet]. 2013 [cited 2016 Apr 25]. http://www.ptsd.va.gov/professional/ assessment/te-measures/life_events_checklist.asp

11. Reichenheim ME, Moraes CL. [Operationalizing the cross-cultural adaptation of epidemiological measurement instruments]. Rev Saude Publica. 2007;41:655-73.

12. Pasquali L. Instrumentos psicológicos: manual prático de elaboração. Brasília: LabPAM; 1999.

13. Passos RB, Figueira I, Mendlowicz MV, Moraes CL, Coutinho ES. Exploratory factor analysis of the Brazilian version of the PostTraumatic Stress Disorder Checklist: civilian version (PCL-C). Rev Bras Psiquiatr. 2012;34:155-61

14. Costa MF, Mendlowicz MV, Vasconcelos AG, Berger W, Luz MP, Figueira I, et al. Confirmatory factor analysis of posttraumatic stress symptoms in Brazilian primary care patients: an examination of seven alternative models. J Anxiety Disord. 2011;25:950-63.

15. American Educational Research Association (AERA); American Psychological Association (APA); National Council on Measurement in Education (NCME). Standards for educational and psychological testing. Washington: AERA Publications; 1999.

16. Cassep-Borges V, Balbinotti MAA, Teodoro MLM. Tradução e validação de conteúdo: uma proposta para a validação de instrumentos. In: Pasquali L, editor. Instrumentação psicológica: 
fundamentos e práticas. Porto Alegre: Artmed; 2010. p. 506-20.

17. Gray MJ, Litz BT, Hsu JL, Lombardo TW. Psychometric properties of the life events checklist. Assessment. 2004;11:330-341.

18. Wilkins KC Lang AJ, Norman SB. Synthesis of the psychometric properties of the PTSD checklist (PCL) military, civilian, and specific versions. Depress Anxiety. 2011;28:596-606.

19. Bae H, Kim D, Koh H, Kim Y, Park JS. Psychometric properties of the life events checklist-korean version. Psychiatry Investig. 2008; 5:163-7.

20. Elhai JD, Gray MJ, Kashdan TB, Franklin CL. Which instruments are most commonly used to assess traumatic event exposure and posttraumatic effects?: A survey of traumatic stress professionals. J Trauma Stress. 2005;18:541-5.

21. Berger W, Mendlowicz MV, Souza WF, Figueira I. Equivalência semântica da versão em português da Post-Traumatic Stress Disorder Checklist - Civilian Version (PCL-C) para rastreamento do transtorno de estresse pós-traumático. Rev Psiquiatr Rio Gd Sul. 2004;26:167-75.

22. Blevins CA, Weathers FW, Davis MT, Witte TK, Domino JL. The Posttraumatic Stress Disorder Checklist for DSM-5 (PCL-5): development and initial psychometric evaluation. J Trauma Stress. 2015;28:489-98.

23. Bovin MJ, Marx BP, Weathers FW, Gallagher MW, Rodriguez $P$ Schnurr PP, et al. Psychometric Properties of the PTSD Checklist for Diagnostic and Statistical Manual of Mental Disorders-Fifth Edition (PCL-5) in veterans. Psychol Assess. 2015 Dec 14. [Epub ahead of print]
24. Hambleton RK. Issues, designs, and technical guidelines for adapting tests into multiple languages and cultures. In: Hambleton RK, Merenda PF, Spielberger CD, editors. Adapting educational and psychological tests for cross-cultural assessment. Mahwah: Lawrence Erlbaum; 2005. p. 3-38.

25. International Test Commission (ITC). Guidelines for translating and adapting tests. [Internet]. 2010 [cited $2016 \mathrm{Apr} 25$ ]. intestcom.org/files/guideline_test_adaptation.pdf

26. Byrne BM, Oakland T, Leong FTL, Van de Vijver F, Hambleton RK, Cheung FM, et al. A critical analysis of cross-cultural research and testing practices: implications for improved education and training in psychology. Train Educ Prof Psychol. 2009;3:94-105.

27. Castro CA, Adler AB. Reconceptualizing combat-related posttraumatic stress disorder as an occupational hazard. In: Adler AB, Bliese PD, Castro CA, editors. Deployment psychology - evidence-based strategies to promote mental health in the military. Washington: APA; 2011. p. 217-42.

\section{Correspondence:}

Eduardo de Paula Lima

Av. Alfredo Balena, 190/705

30310-100, Belo Horizonte, MG - Brazil

E-mail: edpl@hotmail.com 